\title{
Process versus outcome: The sugar window
}

\author{
David A. Fullerton, MD, ${ }^{\mathrm{a}}$ and Thoralf M. Sundt, $\mathrm{MD}^{\mathrm{b}}$
}

All cardiac surgical programs are focused on outcomes, particularly rates of morbidity and mortality. It has long been held that the "processes" of care lead to "outcomes." "However, the relationship between processes and outcomes is complex and indirect; outcomes may be bad even though the processes were optimal. But unlike true surgical outcomes, elements of the processes of care may be measured immediately and thereby provide an opportunity for timely correction. Hence, there is logic to monitoring process measures. A challenge arises, however, if questions arise about the validity of the relationship between process and outcome; one such performance measure is the control of serum glucose in cardiac surgical patients.

In 1997, Zerr and colleagues ${ }^{2}$ retrospectively analyzed data from diabetic cardiac surgical patients who underwent operations between 1987 and 1993 and reported an association of perioperative hyperglycemia and deep wound infections. Reports from other cardiac surgical investigators soon followed supporting this association and suggesting that control of hyperglycemia through use of a continuous insulin infusion (CII) might mitigate its risk. ${ }^{3-6}$ For the most part, these reports were retrospective, single-center studies demonstrating association but not causality. The inference that tight glucose control would benefit cardiac surgical patients was reinforced by van den Berghe and colleagues, ${ }^{7}$ who in 2001 reported that an insulin infusion protocol used to control hyperglycemia reduced morbidity and mortality in a spectrum of critically ill patients. Those groups looking on a national level for levers to improve surgical outcomes noted these reports and began to include postoperative glycemic control as a measure of cardiac surgical quality.

The Medicare Surgical Infection Prevention (SIP) project was begun in the fall of 2003, and hospitals began collecting core measure data for SIP with patient discharges beginning July 1, 2004. The SIP set of process measures subsequently transitioned to the Surgical Care Improvement Project

\footnotetext{
From the Division of Cardiothoracic Surgery, ${ }^{\text {a }}$ University of Colorado School of Medicine, Aurora, Colo; and Division of Cardiac Surgery, ${ }^{\mathrm{b}}$ Massachusetts General Hospital, Boston, Mass.

Dr Fullerton is President, The Society of Thoracic Surgeons, 2014-2015. Dr Sundt is Vice-President, American Association for Thoracic Surgery, 2014-2015.

This article is being published simultaneously in the Journal of Thoracic and Cardiovascular Surgery and The Annals of Thoracic Surgery.

Address for reprints: David A. Fullerton, MD, Division of Cardiothoracic Surgery, University of Colorado School of Medicine, 12631 E 17th Ave, MS C-310, Rm 6602, Aurora, CO 80045 (E-mail: david.fullerton@ucdenver.edu).

J Thorac Cardiovasc Surg 2014;148:2458-60

$0022-5223 / \$ 36.00$

Copyright (C) 2014 by The American Association for Thoracic Surgery and The Society of Thoracic Surgeons

http://dx.doi.org/10.1016/j.jtcvs.2014.10.076
}

(SCIP) measures effective July 1, 2006. The SCIP is a partnership of national organizations with the laudable commitment to reducing the rate of surgical complications. ${ }^{8,9}$ The SCIP partners include a steering committee with representatives of 10 national organizations that support the project. It has developed 20 process measures, of which there are nine publicly reported SCIP measures; of these, six focus on the prevention of postoperative infection. The measures once established are monitored and updated quarterly by a "technical expert panel" to ensure their validity.

One of the six infection-prevention SCIP measures pertains to the control of postoperative serum glucose and has been in effect since 2009. The Centers for Medicare and Medicaid Services are the designated stewards of this measure responsible for ongoing maintenance, and the measure has been endorsed by the National Quality Forum. As originally implemented, this SCIP measure called for the 6:00 AM serum glucose on postoperative days 1 and 2 to be less than 200 $\mathrm{mg} / \mathrm{dL}$ in cardiac surgical patients. Effective January 1, 2014, this measure was changed: the serum glucose is to be less than $180 \mathrm{mg} / \mathrm{dL}$ during postoperative hours 18 to 24 . The time interval begins at the "anesthesia end time." 10

There are strong financial incentives for hospitals to comply with the SCIP measures. Collection of these data by hospitals is voluntary. However, failure to report performance on these measures results in a $2 \%$ reduction hospital reimbursement from the Centers for Medicare and Medicaid Services. ${ }^{11}$ The results of a given hospital's data are reported on the Hospital Compare Web site (http:// www.hospitalcompare.hhs.gov). ${ }^{11}$ Further, beginning in 2014, hospital reimbursement is penalized for failure to achieve the measures under the "value-based purchasing" by Centers for Medicare and Medicaid Services, jeopardizing millions of dollars per year of a given hospital's revenue.

Therefore, hospitals place significant emphasis on SCIP measure compliance. Unfortunately, pursuit of compliance with such measures can be vexing at the least and arguably counterproductive at the worst. Cardiac surgical programs are being forced to build robust systems of care around the imperative to control the serum glucose level despite flimsy evidence to support their validity.

Hyperglycemia seems to be a ubiquitous finding in postoperative cardiac surgical patients. Efforts to comply with the SCIP measure have led to a maddening obsession with even minor elevations in serum glucose during the time in which the process measure is determined, the "sugar window." The effort to avoid even minor elevations of glucose can lead to perverse activities that may actually be harmful, such as patients not being fed until after 
the "sugar window" has closed, disrupting their usual postoperative convalescent progress.

The administration of a CII is now commonplace as prophylaxis against even the possibility of postoperative hyperglycemia, adding cost and complexity to the care of the patient. This is done despite evidence that even a CII provides no assurance of achieving compliance with the glucose measure. ${ }^{12,13}$ The safe practice of CII use, of course, often requires that a patient be monitored in an intensive care unit even in the absence of other reasons for the patient to be there, artificially prolonging postoperative intensive care unit stays and thereby increasing hospital length of stay and costs. This is surely counter to simultaneous pressures to improve the "value equation" of cost/quality in health care. In some cardiac surgical programs, patients routinely receive a CII for the first 72 hours postoperatively to control serum glucose $!^{14}$

The subject of compliance (and therefore noncompliance) with the glucose measure is a constant topic of hospital quality meetings, further absorbing efforts that might be better spent elsewhere and increasing administrative costs. A cottage industry of consultants has sprung up eager to offer advice on how a given hospital may comply. One of us (D.A.F.) receives weekly reports from the hospital "glucose investigators" that describe in detail each instance of noncompliance. Efforts to comply with the glucose SCIP measure have emerged as a dominant focus in cardiac surgical programs across the country. All of this is happening despite the lack of evidence that compliance with the SCIP process measure of glucose control actually improves quality.

The literature does not support the glucose SCIP measure as a quality metric. To the contrary, a growing body of data demonstrates no difference in morbidity or mortality in patients that do or do not comply with the glucose SCIP measure. ${ }^{11,12,15}$ Further, compliance with the glucose control SCIP measure does not reflect glycemic control during the perioperative period. ${ }^{12,13}$

More importantly, efforts to comply with this performance metric may be harmful. The risk of iatrogenic hypoglycemia induced by attempted SCIP measure compliance is real and may jeopardize patient safety. The Normoglycemia in Intensive Care Evaluation-Survival Using Glucose Algorithm Regulation (NICE-SUGAR) study confirmed an increased mortality from iatrogenic hypoglycemia in the group of patients treated with aggressive glycemic control. ${ }^{16}$ It is ironic that no requirement exists for the reporting of iatrogenic hypoglycemia.

We appreciate that it is difficult to determine quality in surgical care and that although the outcome is the most important variable to measure, an argument can be made for measuring the process by which outcomes are derived. But when the focus is so intensely placed on individual process measures of care disconnected from the outcome, particularly when a given process measure may be harmful, a significant problem exists. It is a mistake to place such emphasis on questionable process measures and to link them to millions of dollars of hospital reimbursement. Such focus implies that process measures are "quality" in and of themselves, rather than simply tools by which good outcomes may be attained.

There can be no question that the profession of cardiothoracic surgery is one committed to quality. The fact that greater than $95 \%$ of all cardiac surgical programs voluntarily submit data on each patient to a national database and approximately $50 \%$ of these programs publically report their data voluntarily speaks to this commitment. The question is: who is in the best position to determine what constitutes quality in cardiac surgery? The answer is the profession itself. It is the profession that is most invested, knowledgeable, and capable. Especially now, at the cusp of significant change in the financial model of health care, it is incumbent upon the profession to determine and continuously reevaluate the quality metrics of cardiothoracic surgical care. We must step up and insist on a voice in evaluating and maintaining appropriate national measures to ensure that they are in alignment with the laudable intent of their sponsors. We should insist through our national organizations on a place at the table.

\section{References}

1. Donabedian A. Quality of care, how can it be assessed? JAMA. 1988;260:1743-8.

2. Zerr KJ, Furnary AP, Grunkemeier GL, Bookin S, Kanhere V, Starr A. Glucose control lowers the risk of wound infection in diabetics after open heart operations. Ann Thorac Surg. 1997;63:356-61.

3. Furnary AP, Zerr KJ, Grunkemeier GL, Starr A. Continuous intravenous insulin infusion reduces the incidence of deep sternal wound infection in diabetic patients after cardiac surgical procedures. Ann Thorac Surg. 1999;67: 352-62.

4. Jones KW, Cain AS, Mitchell JH, Millar RC, Rimmasch HL, French TK, et al Hyperglycemia predicts mortality after CABG: postoperative hyperglycemia predicts dramatic increases in mortality after coronary artery bypass graft surgery. J Diabetes Comp. 2008;365-70.

5. Lazar HL, Chipkin SR, Fitzgerald CA, Boa Y, Cabral H, Apstein CS. Tigh glycemic control in diabetic coronary artery bypass graft patients improves perioperative outcomes and decreases recurrent ischemic events. Circulation. 2014;109:1497-502.

6. Carr JL, Selke FW, Fey M, Doyle MJ, Krempin JA, de la Torre R, et al. Implementing tight glucose control after coronary artery bypass surgery Ann Thorac Surg. 2005;80:902-9.

7. Van den Berghe G, Wouters P, Weekers F, Verwaest C, Bruyninckx F, Schetz M, et al. Intensive insulin therapy in the surgical intensive care unit. $N$ Engl J Med. 2001;345:1359-67.

8. Bratzler DW, Hunt DR. The surgical infection prevention care improvement projects: national initiatives to improve outcomes for patients having surgery Clin Infect Dis. 2006;43:322-30.

9. Clancy CM. SCIP: making complications of surgery the exception rather than the rule. AORN J. 2008;87:621-4.

10. Surgical Care Improvement Project (SCIP). Fact sheet. Summary of SCIP measure changes for 01/01/2014 discharges. Available at: http://www.jointcommission. org/assets/1/6/SCIP-FactSheet_010114v4.3.pdf.

11. Stulberg JJ, Delaney CP, Veuhauser DV, Aron DC, Fu P, Koroukian SM Adherence to Surgical Care Improvement Project measures and the association with postoperative infections. JAMA. 2010;303:2479-85.

12. McDonnell ME, Alexanian SM, Junqueira A, Cabral H, Lazar HL. A relevance of the Surgical Care Improvement Project on glycemic control in patients undergoing cardiac surgery who receive continuous insulin infusions. J Thorac Cardiovasc Surg. 2013;145:590-7. 
13. Murphy MA, Whitman I, Campfield A, Moxey E, Haddad M, Whitman G. Intense implementation of a strict insulin infusion protocol does not guarantee postoperative glycemic control. J Am Coll Surg. 2010;211:465-9.

14. Desai SP, Henry LL, Holmes SD, Hunt SL, Martin CT, Hebsur S, et al. Strict versus liberal target range for perioperative glucose in patients undergoing coronary artery bypass grafting: a prospective randomized controlled trial. J Thorac Cardiovasc Surg. 2012;143:318-25.
15. LaPar DJ, Isbell JN, Kern JA, Ailawadi G, Kron IL. Surgical Care Improvement Project measure for postoperative glucose control should not be used as a measure of quality after cardiac surgery. J Thorac Cardiovasc Surg. 2014;147: 1041-8.

16. The NICE-SUGAR Study InvestigatorsFinfer S, Chittock DR, Su SY, Blair D, Foster D, Dhingra V, et al. Intensive versus conventional glucose control in critically ill patients. $N$ Engl J Med. 2009;360:1283-97. 